[Agr. Biol. Chem., Vol. 36, No. 3, p. 390 397, 1972]

\title{
Non-Enzymic Browning of Soy Sauce
}

\author{
Comparison of the Browning of Soy Sauce with that \\ of a Sugar-amino Acid Model System ${ }^{\dagger}$
}

\author{
By Hironaga Hashiba \\ Noda Institute for Scientific Research, Noda-shi, Chiba-ken, Japan \\ Received August 25, 1971
}

\begin{abstract}
The browning reaction in soy sauce was compared with that in the model system containing sugars (glucose $4 \%$, xylose $1 \%$ ) and amino acids (glycine 5\%, glutamic acid $5 \%$ ). In both cases, browning was developed on heating or static oxidation (spontaneous oxidation). On shaking oxidation (obliged oxidation), on the contrary, browning was observed only in soy sauce, and in the model system it was rather repressed by this treatment. The brown pigments in the model system were fractionated into two components, designated as $F-A$ and $F-B$, by gel filtration with Sephadex G-25. The amount of F-A was increased on oxidation, and that of $F-B$ was increased on heating but decreased on oxidation. The color of F-A was dark tone and that of F-B was light tone. F-A and F-B were suggested to be analogous to brown pigment P-I and P-III in soy sauce, respectively, judging from the results of gel filtration, characteristics of the color and UV absorption spectra.

Amino acid solutions (hydrolyzates of soybean) resembled soy sauce more closely than the model system in the browning behaviors on shaking oxidation and in chromatographic patterns of brown pigments on Sephadex G-25.

In addition, not only glycine and glutamic acid but also many kinds of amino acids were found to be lost considerably during the browning of soy sauce.
\end{abstract}

It is well known that the non-enzymic browning of soy sauce occurs during pasteurization process and storage. Such "browning," especially so-called "oxidative browning" is undesirable because it is in many cases accompanied by the deterioration of taste and flavor. But the mechanism of the browning reaction and the origin of pigments in soy sauce remain obscure, mainly because of the complexity of the components of soy sauce. Kato et al..$^{11}$ postulated that 3-deoxyosones and glucosone were important intermediates in the browning of soy sauce. Okuhara et al., ${ }^{2}$ however, suggested that the role of glucose and amino acids were not so significant but

$\dagger$ Presented at the Annual Meeting of the Agricultural Chemical Society of Japan, Tokyo, April 1, 1971. peptides and other unknown factors were important in the browning since the browning rate of soy sauce was much more rapid than that of a simple mixture of amino acids and sugars. The author ${ }^{31}$ previously fractionated the pigments in soy sauce into three components by gel filtration with Sephadex G-25 and examined some characteristics of them. The current study was designed to clarify the role of sugars and amino acids in the non-enzymic browning of soy sauce and moreover to investigate the origin of soy sauce pigments. Then the browning reaction in a simple sugar-amino acid model system was investigated by gel filtration and UV absorption spectra, and similarities or dissimilarities of the browning reactions between soy sauce and the model system were examined. Finally 
contribution of sugars and amino acids to the non-enzymic browning of soy sauce was discussed.

\section{MATERIALS AND METHODS}

Model system. Model system contained glucose $(4 \%)$, xylose $(10)$, glycine $(50)$, glutamic acid $(5 \%)$ and $\mathrm{NaCl}(180)$ in $0.2 \mathrm{M}$ phosphate buffer ( $\mathrm{pH} 5.0$ ). Because of the complexity of the chemical composition of soy sauce, it was difficult to prepare a simple model system resembling soy sauce. The sugars and amino acids selected were chosen to represent major components in soy sauce.

Soy sauce and amino acid solution. Naturally brewed and not pasteurized soy sauce and commercial seasonings of amino acid solution (from Ajinomoto, Co., Ltd. and from Nihon Rikagaku Yakuhin, Co., Ltd.) were used.

Browning reaction on heating. Samples were autoclaved $\left(1 \mathrm{~kg} / \mathrm{cm}^{2}\right)$ for $5 \mathrm{~min}$ without sealing. This heating condition was close to industrial pasteurizing condition in developing the browning of soy sauce.

Browning reaction on oxidation. Five $\mathrm{ml}$ of samples were taken into test tubes $(1.5 \times 16 \mathrm{~cm})$ and then left still or shaked at $230 \mathrm{rpm}$ at $30^{\circ} \mathrm{C}$.

Chromatography on Sephadex G-25. Sephadex G-25 fine was used and the usual conditions of chromatography were as follows: Column size, $1.7 \times 100 \mathrm{~cm}$; Flow rate, $20 \mathrm{ml} / \mathrm{hr}$, Fraction volume, $6.6 \mathrm{ml}$.

UV and visible absorption spectra. They were measured with a Hitachi 139-Spectrophotometer.

Determination of total sugar, amino acids and total amino-N. Total sugar was determined by the phenol$\mathrm{H}_{2} \mathrm{SO}_{4}$ method, 4' amino acids were analyzed with a Hitachi 034-Analyzer, and total amino- $N$ was determined by the ninhydrin method of Rosen.

\section{RESULTS}

Browning of soy sauce and the model system

1. Time course of the oxidative brotoning. The color of soy sauce increased on static oxidation (spontaneous oxidation) and remark- ably on shaking oxidation (obliged oxidation) as shown in Fig. 1-1. The increase of color intensities at $555 \mathrm{~m} \mu$ was greater on shaking oxidation than on static oxidation, but at 470 $\mathrm{m} \mu$ the results were just the opposite. It is considered that as the yellow tone in soy sauce changes to brown or black tone on oxidation, the light absorbance decreases at lower wavelengths and increases at higher wavelengths. On the other hand, in the model system, the color increased on static oxidation but not so

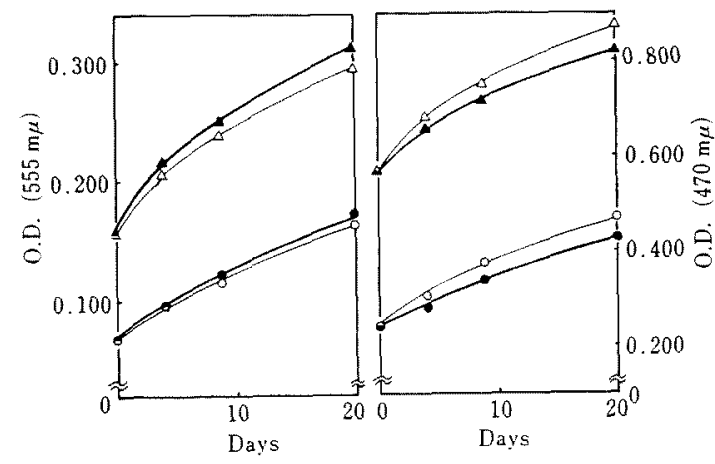

FIG. 1-1. Browning of Soy Sauce on Oxidation.

$\triangle, \Delta$, heated; $O, \bullet$, not heated; $\triangle, O$, static oxidation; A. shaking oxidation.

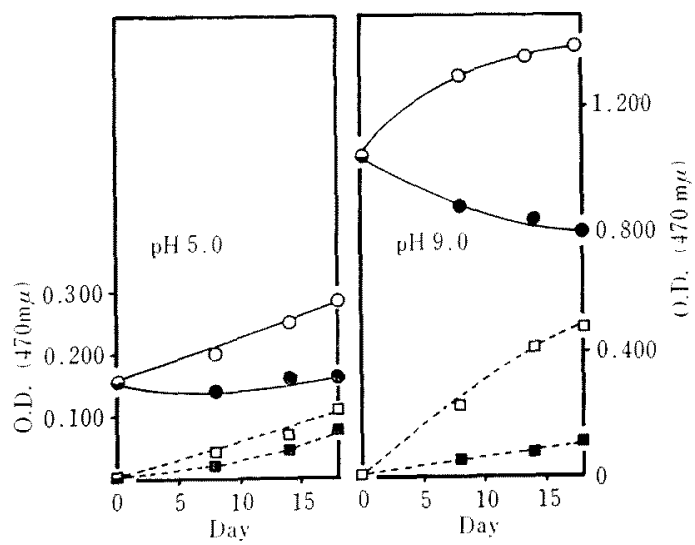

FIG. 1-2. Changes of Color Intensities of the Model System on Oxidation.

O, heated samples; $\square, \mathbf{0}$, not heated samples; $0, \square$, static oxidation; 
much on shaking oxidation, and it was even decolorized in preheating samples (Fig. 1-2). This decolorizing phenomena were observed more remarkably at $\mathrm{pH} 9.0$.

2. Effect of heating time on the oxidative browning of soy sauce and the model system. Figure 2 shows the color increase on shaking oxidation of the samples treated for various heating times. The color of soy sauce and the model system increased at nearly the same rate on heating although a little lag was observed in the model system. All samples of soy sauce browned significantly on shaking oxidation, and the longer the heating time the greater the color increase on oxidation. On the contrary, the color of the model system was decolorized on shaking oxidation except the samples heated for $0 \sim 1 \mathrm{hr}$.

Column chromatography of the brown pigments in the model system

1. The brown pigments in oxidative or heat browning. As shown in Fig. 3, the pigments were fractionated into two components (designated as F-A and F-B), while those in soy sauce were fractionated into three components. The pigment $\mathrm{F}-\mathrm{A}$ was produced mainly in oxidative browning reaction but the pigment F-B was mainly caused in heat browning

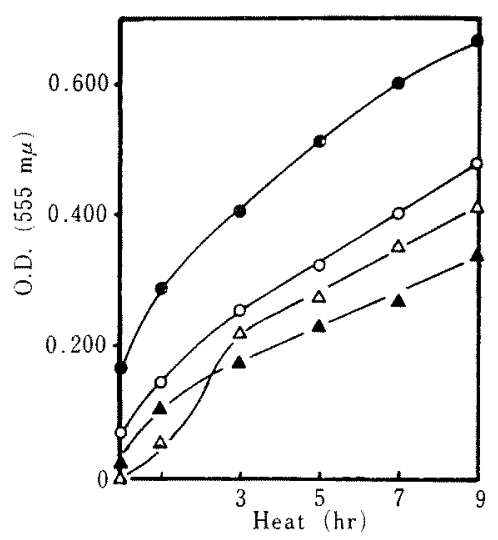

FIG. 2. Effect of Heating Time on the Oxidative Browning of Soy Sauce and the Model System.

Samples were heated in boiling water and then oxidized by shaking at $30^{\circ} \mathrm{C}$ for 2 weeks.

Soy sauce: $\bigcirc$, before oxidation; $\bullet$, after oxida. tion.

Model system: $\triangle$, before oxidation; $\boldsymbol{\Lambda}$, after oxidation.

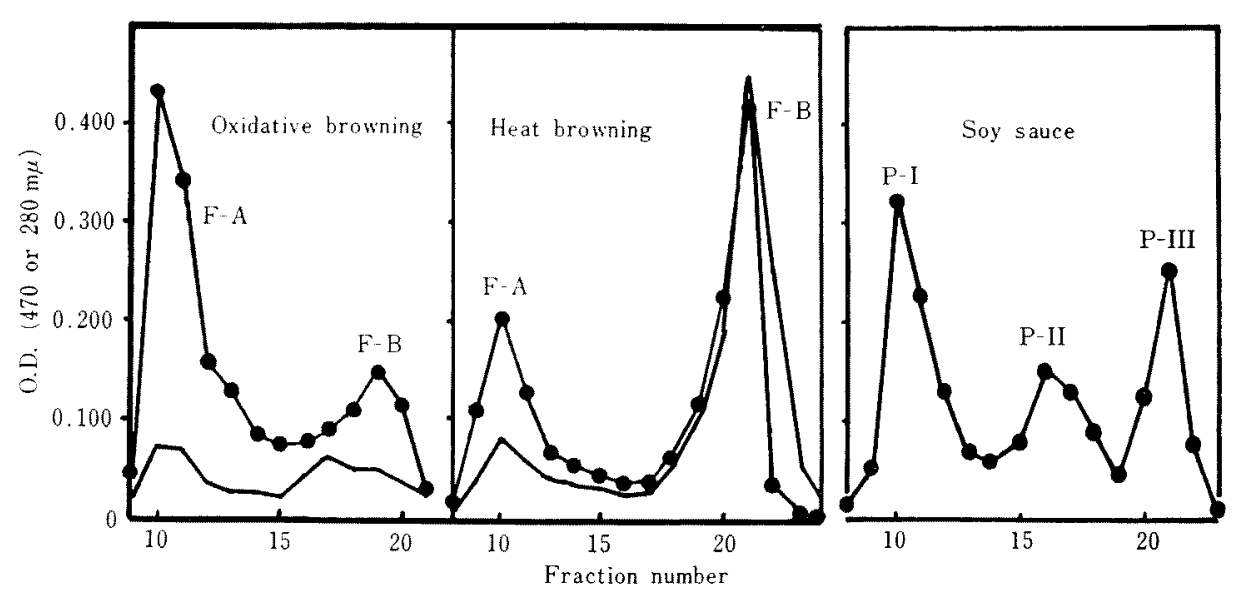

FIG. 3. Column Chromatogram of Brown Pigments in the Model System on Sephadex G-25.

Oxidative browning; sample was kept at $30^{\circ} \mathrm{C}$ for 2 weeks. Heat browning; sample was heated $120^{\circ} \mathrm{C}$ for $5 \mathrm{~min}$.

- O. D. at $470 \mathrm{~m} /$; — O. D. at $280 \mathrm{~m} \mu$. 
reaction. The former was weak in absorbance at $280 \mathrm{~m} \mu$, but the latter was strong. From the chromatogram shown in Fig. 3, it was supposed that $\mathrm{F}-\mathrm{A}$ and $\mathrm{F}-\mathrm{B}$ were very similar to $\mathrm{P}-\mathrm{I}$ and $\mathrm{P}-\mathrm{III}$ in soy sauce, respectively.

2. Changes of $F-A$ and $F-B$ on oxidation. As shown in Fig. 4, F-A increased but F-B decreased remarkably on oxidation. This phenomenon was also observed in the same treatment of $\mathrm{P}-\mathrm{I}$ and $\mathrm{P}-\mathrm{III}$ in soy sauce.

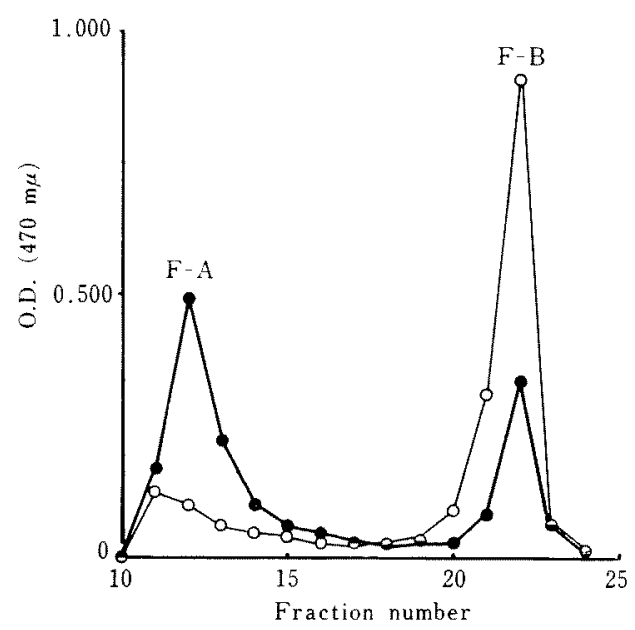

FIG. 4. Changes of the Brown Pigments in the Model System on a Sephadex G-25 Column on Oxidation.

0 , initial;* $*$ after oxidation for 9 days.

* The model system was heated at $120^{\circ} \mathrm{C}$ for $5 \mathrm{~min}$ initially.

3. Color characteristics of $F-A$ and $F-B$. Percent distributions of color constituents in

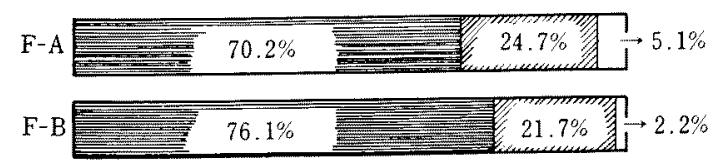

FIG. 5. Percent Distributions of Light Absorbance at $440 \mathrm{~m} \%, 520 \mathrm{~m} \mu$ and $630 \mathrm{~m} \mu$ in $\mathrm{F}-\mathrm{A}$ and $\mathrm{F}-\mathrm{B}$.

Sum of light absorbance at $440 \mathrm{~m} \mu, 520 \mathrm{~m} \mu$ and $630 \mathrm{~m} \mu$ was taken as $100^{\circ} \mathrm{o}$.

=, Yellow (440 m $\mu) ;$ W/It, Red (520 mu); Blue $(630 \mathrm{~m} / \mathrm{s})$.
$\mathrm{F}-\mathrm{A}$ and $\mathrm{F}-\mathrm{B}$ were shown in Fig. 5. The color of $\mathrm{F}-\mathrm{A}$ was stronger in red and blue tones than that of $\mathrm{F}-\mathrm{B}$, and the color of $\mathrm{F}-\mathrm{B}$ was stronger in yellow tone than that of $\mathrm{F}-\mathrm{A}$. Also from the viewpoint of these color characteristics similarities of F-A and F-B to respective P-I and P-III in soy sauce were admitted.

\section{Comparison of $U V$ absorption spectra between soy} sauce and the model system

Changes of absorption spectra of the model system on oxidation were shown in Fig. 6-1. Absorption maximum at $290 \mathrm{~m} \mu$, which was produced in heat browning decreased gradually and the peak disappeared on oxidation.

The same results were observed in the fractionated brown pigments $\mathrm{F}-\mathrm{A}$ and $\mathrm{F}-\mathrm{B}$, that is, a sharp absorption maximum at 290 $\mathrm{m} \mu$ in $\mathrm{F}-\mathrm{B}$ and a broad absorption at $290 \sim 320$ $\mathrm{m} \mu$ in $\mathrm{F}-\mathrm{A}$ before oxidation were remarkably diminished on oxidation as shown in Fig. 6-2.

On the other hand, changes of UV absorption spectra of soy sauce in the browning reaction must have complicated features, because soy sauce contained such strong UV absorbents as tyrosine, phenylalanine, nucleotides and so on. Therefore, UV difference spectra of the heated or the oxidized soy sauce were examined (Fig. 7). The changes

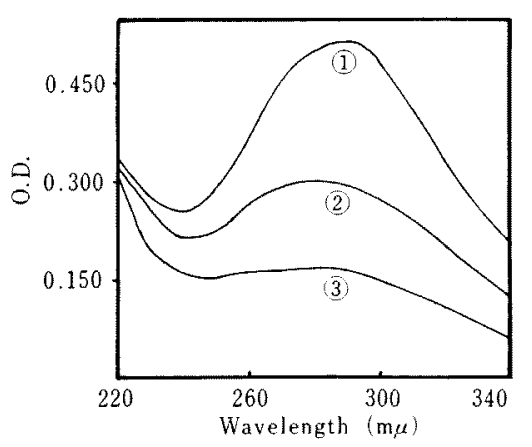

FIG. 6-1. Changes of UV Absorption Spectra of the Model System on Oxidation.

(1) initial; (2) after 10 days; (3) after 20 days.

* The model system was heated at $120 \mathrm{C}$ for 5 min initially. 


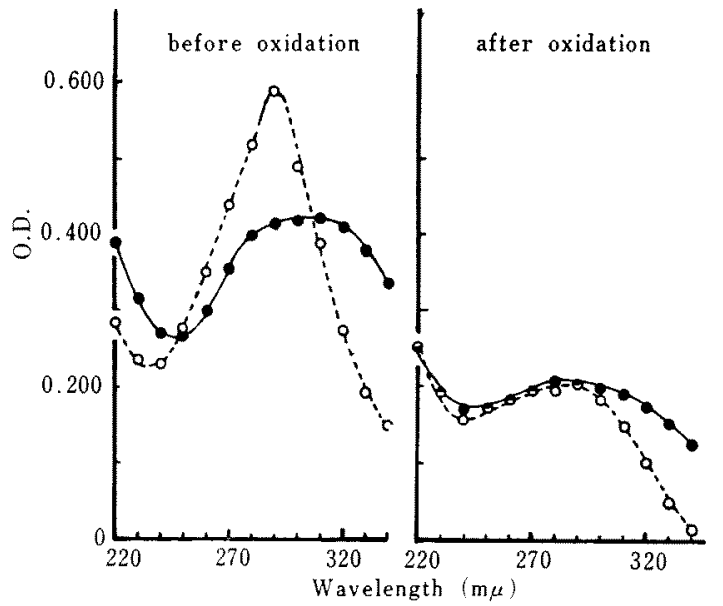

FIG. 6-2. Changes of UV Absorption Spectra of $P-A$ and $P-B$ before and after Oxidation.

- $\mathrm{P}-\mathrm{A} ; \mathrm{O}, \mathrm{P}-\mathrm{B}$.

Oxidation: 10 days' shaking at $30^{\circ} \mathrm{C}$.

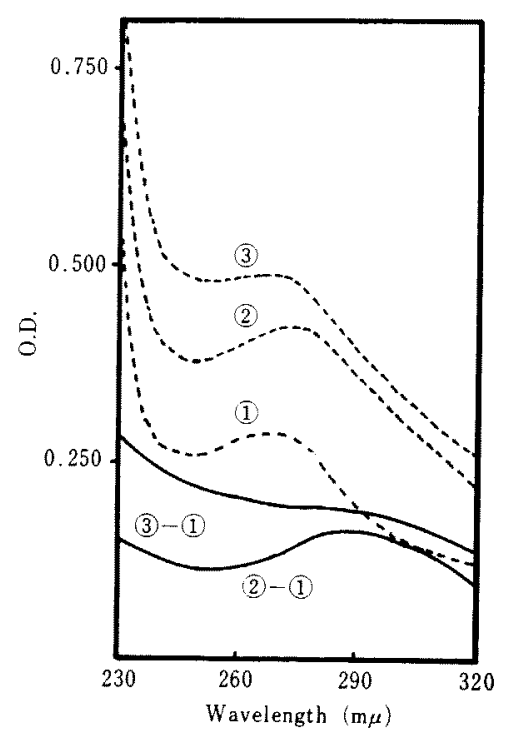

FIG. 7. Changes of UV Absorption Spectra of Soy Sauce on Heating and Oxidation.

(1) soy sauce; (2) heated soy sauce; (3) oxidized soy sauce. of UV absorption spectra of soy sauce during heat browning (Fig. 7, (2)-(1)) resembled that of the model system obtained on heating (Fig. 6-1, (1)). Moreover, changes of UV absorption spectra of soy sauce during oxidative browning, shown as the difference spectrum (3)-(1) in Fig. 7, were also very close to those of the model system (Fig. 6-(1), (3)), that is to say, maximum and minimum absorptions gradually disappeared. From the results of UV absorptions, it is also suggested that amino-carbonyl reactions affect the oxidative browning of soy sauce.

\section{The browning of amino acid solution}

1. The oxidative browning and column chromatography. The browning reactions of two commerical seasonings of amino acid solution (acid hydrolyzates of soybean) were investigated as an example of a little more complex system than the model system. The value of amino- $\mathrm{N}$ was adjusted to about $0.85 \%$. Then, glucose and xylose were added until the final concentrations were $4 \%$ and $1 \%$, respectively. The concentrations of sugars and amino- $\mathrm{N}$ in the amino acid solutions were almost same to those in soy sauce. The brown pigments formed on heating $\left(120^{\circ} \mathrm{C}, 5 \mathrm{~min}\right)$ in these amino acid solutions were separated into three peaks by gel filtration with Sephadex G-25 as shown in Fig. 8-1. This chromatogram resembled closely that of soy sauce. Moreover, the browning reaction in the amino acid solutions developed even on shaking oxidation as well as that in soy sauce (Fig. 8-2). Therefore, the browning reaction in the amino acid solution may be more analogous to that in soy sauce than that in the model system.

2. Comparison of the browning among soy sauce, model system and amino acid solutions. The samples were heated $\left(120^{\circ} \mathrm{C}, 5 \mathrm{~min}\right)$ at the same time and the increase of light absorbance or the decrease of amino- $\mathrm{N}$ and total sugar were compared (Table I). The increase of light 


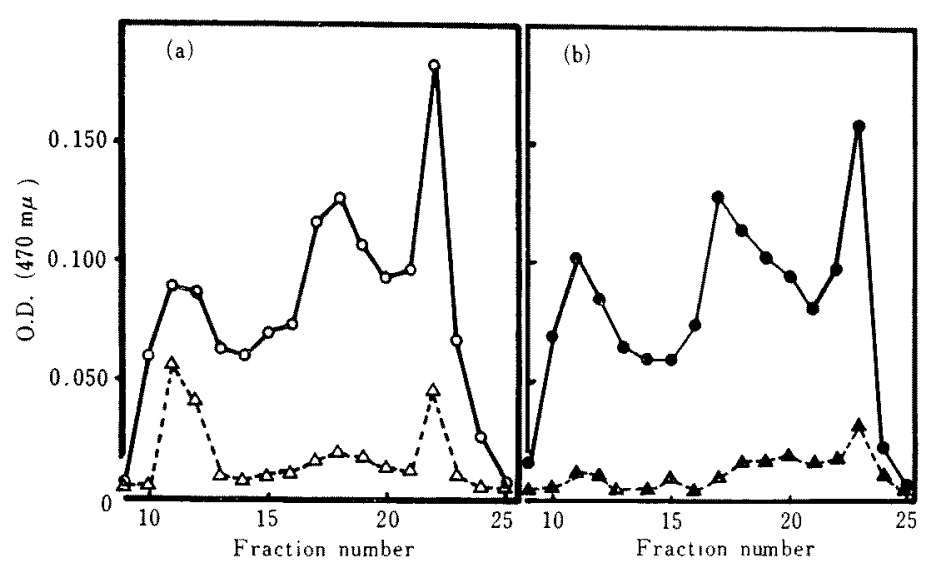

FIG. 8-1. Column Chromatogram of Amino Acid Solution on Sephadex G-25.

Each amino acid solution was supplemented with glucose (final concentration was $4 \%$ ) and xylose (final concentration was $1 \%$ ), and then heated at $120^{\circ} \mathrm{C}$ for $5 \mathrm{~min}$.

(a) amino acid solution from Ajinomoto Co., Ltd.; (b) amino acid solution from Nihon Rikagaku Yakuhin Co., Ltd.; $\Delta, \boldsymbol{\Delta}$, before heating; $0, \boldsymbol{\theta}$, after heating.

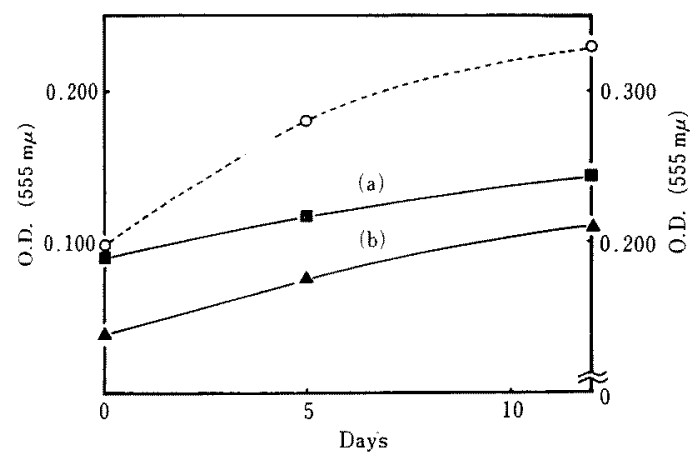

FIG. 8-2. Browning of Amino Acid Solution on Shaking Oxidation.

Each amino acid solution was supplemented with glucose $(4 \%)$ and $x y$ lose $(1 \%)$ and heated $120^{\circ} \mathrm{C}$ for $5 \mathrm{~min}$ before oxidation.

- amino acid solution from Ajinomoto Co., Ltd.; $\boldsymbol{\Delta}$, amino acid solution from Nihon Rikagaku Yakuhin Co., Ltd.; $\bigcirc$, soy sauce.

absorbance at $290 \mathrm{~m} \mu$ was proportional to that at 470 and $555 \mathrm{~m} \mu$. Total sugar was decreased remarkably in the model system but little were decreased in the others. The values of total amino- $\mathrm{N}$ were almost uneffected in all samples. Generally, the browning of the
Table I. Changes of UV absorption, Total amino-N and Sugar during Heat Browning

\begin{tabular}{|c|c|c|c|c|c|}
\hline & & O. D.a) & & & \\
\hline & 290 & 470 & 555 & N & sugar \\
\hline & $\mathrm{m} \mu$ & $\mathrm{m} /$ & $\mathrm{m} \mu$ & & \\
\hline Soy sauce & 0.224 & 0.300 & 0.092 & $0.84 \%$ & 3.890 \\
\hline $\begin{array}{l}\text { Heated soy } \\
\text { sauce }\end{array}$ & 0.370 & 0.489 & 0.148 & $0.840^{\circ}$ & $3.89 \%$ \\
\hline Net increase & 0.146 & 0.189 & 0.056 & - & - \\
\hline Model system & 0.000 & 0.000 & 0.000 & $1.340_{0}$ & $5.00 \%$ \\
\hline $\begin{array}{l}\text { Heated model } \\
\text { system }\end{array}$ & 0.330 & 0.370 & 0.080 & $1.32 \%$ & $3.69 \%$ \\
\hline Net increase & 0.330 & 0.370 & 0.080 & -0.020 & -1.4096 \\
\hline $\begin{array}{l}\text { Amino acid } \\
\text { soln. (a) }\end{array}$ & 0.088 & 0.077 & 0.025 & $0.860^{\circ}$ & $5.00 \%$ \\
\hline Heated amino & 0.174 & 0.163 & 0.046 & $0.85 \circ$ & $5.00 \%$ \\
\hline
\end{tabular}

Heated amino $0.174 \quad 0.163 \quad 0.046 \quad 0.850_{0} \quad 5.00 \%$ acid soln. (a)

\begin{tabular}{lllllll} 
Net increase & 0.086 & 0.086 & 0.021 & $-0.01 \%$ & - \\
\hline Amino acid & 0.038 & 0.027 & 0.012 & $0.84 \%$ & $5.00 \%$
\end{tabular} soln. (b)

Heated amino $\quad 0.074 \quad 0.056 \quad 0.019 \quad 0.84 \% \quad 5.00 \%$ acid soln. (b)

Net increase $0.0360 .0290 .007 \quad \ldots \quad$ -

a) O.D. at 470 or $555 \mathrm{~m} \mu$ were measured after diluting samples with 25 -fold water and O.D. at 290 mu were measured after diluting with $25 \times 25$-fold water. 
amino acid solutions was less than that of soy sauce in spite of the same concentrations of sugar and amino-N. It is considered that soy sauce may contain some compounds accelerating the browning reaction.

\section{DISCUSSION}

The present experiment suggested an origin of pigments in soy sauce and a significant contribution of sugars and amino acids to the browning of soy sauce, though some discrepancies were present between soy sauce and the model system. For example, some differences in shaking oxidation were observed between soy sauce and the model system as shown in Fig. 1-1 and 1-2. In the shaking oxidation, the browning of the model system did not so much proceed in the over-all measurement of the color, probably for the reason that the brown pigment $(\mathrm{F}-\mathrm{B})$ produced on heating is susceptible to the excess oxidation. Besides, the pigments in the model system were fractionated into two components while those in soy sauce consisted of three components on chromatogram.

On the other hand, the browning of the amino acid solutions resembled more closely that of soy sauce than that of the model system (Fig. 8-1, 2). It was inferred from these results that the browning of soy sauce was concerned not only with the sugars and the amino acids used in the present model system but also with other amino acids or unknown substances. Omata et al. ${ }^{61}$ have reported that the basic amino acids such as lysine, histidine and arginine were effective in the browning reaction. Therefore it was expected that the loss of these amino acids was heavier than the others in the browning of soy sauce. However, no special tendencies to decomposition were observed among acidic, neutral or basic amino acids during the browning reaction as shown in Table II. Almost all amino acids were lost $10 \sim 40 \%$ in the oxidative browning, contrary to the heat browning where the loss of amino acids were little. The main part of the loss of glutamic acid during heat browning may be caused by pyrolysis but not by browning reaction. For the reference, losses of total sugar and amino$\mathrm{N}$ were calculated. Total sugar was lost drastically in both browning reactions but the loss of amino-N was comparatively smaller than that of amino acids. Free amino groups were supposed to remain even after the decomposition of amino acids in the browning reaction.

It was notable that in the oxidative browning both sugars and amino acids disappeared equally, but in the heat browning, in spite of the drastic decrease of sugars, amino acids were comparatively uneffected. It was con-

\begin{tabular}{|c|c|c|c|c|c|}
\hline \multirow[t]{2}{*}{$\begin{array}{r}\text { TABLE II } \\
\text { ON }\end{array}$} & \multicolumn{3}{|c|}{$\begin{array}{l}\text { EFFECTS OF OXIDATION } \\
\text { THE CONCENTRATIONS OF } \\
\text { ACIDS IN SOY SAUCE }\end{array}$} & \multicolumn{2}{|c|}{$\begin{array}{l}\text { AND HEATING } \\
\text { AMINO }\end{array}$} \\
\hline & $\begin{array}{l}\text { Con- } \\
\text { trol }\end{array}$ & $\begin{array}{l}\text { After } \\
\text { oxida- } \\
\text { tion }^{a}\end{array}$ & $\begin{array}{l}\text { Loss } \\
\text { of } \\
\text { con- } \\
\text { tent }\end{array}$ & $\begin{array}{l}\text { After } \\
\text { heat- } \\
\text { ingbl }\end{array}$ & $\begin{array}{l}\text { Loss } \\
\text { of } \\
\text { con- } \\
\text { tent }\end{array}$ \\
\hline & $34.2^{\circ 1}$ & $32.3^{c 1}$ & $5.60_{0}^{\circ}$ & $34.2^{c 1}$ & 0.09 \\
\hline & 23.9 & 20.8 & 13.0 & 23.6 & 1.1 \\
\hline & 37.1 & 33.1 & 10.7 & 36.8 & 0.7 \\
\hline & 84.9 & 70.3 & 17.3 & 61.4 & 27.7 \\
\hline & 22.0 & 18.6 & 15.2 & 22.0 & 0.0 \\
\hline & 32.4 & 28.0 & 13.6 & 28.5 & 12.1 \\
\hline & 58.5 & 37.7 & 35.6 & 58.1 & 0.6 \\
\hline & 37.4 & 25.1 & 32.9 & 37.4 & 0.0 \\
\hline & 8.8 & 5.6 & 36.1 & 8.4 & 5.1 \\
\hline & 33.9 & 26.3 & 22.4 & 33.9 & 0.0 \\
\hline & 52.9 & 39.5 & 25.3 & 52.0 & 1.7 \\
\hline & 24.0 & 14.7 & 38.9 & 24.0 & 0.0 \\
\hline & 35.7 & 28.3 & 20.6 & 33.1 & 7.4 \\
\hline & 5.2 & 2.9 & 44.0 & 4.7 & 10.5 \\
\hline & 107.7 & 101.2 & 6.0 & 106.4 & 1.2 \\
\hline & 8.0 & 6.9 & 13.3 & 7.3 & 8.7 \\
\hline ino-N & 688.0 & 633.0 & 8.0 & 653.6 & 5.0 \\
\hline$g a T^{2}$ & 330.0 & 241.0 & 27.0 & 229.0 & 30.6 \\
\hline D. .555 & 0.094 & 0.840 & - & 0.660 & - \\
\hline
\end{tabular}

a. Samples were kept at $30^{\circ} \mathrm{C}$ for 75 days.

b) Samples were autoclaved $\left(1 \mathrm{~kg} / \mathrm{cm}^{2}\right)$ for $60 \mathrm{~min}$.

c) moles $/ \mathrm{ml}$.

d) Calculated as glucose. 
sidered that both sugars and amino acids were involved in the oxidative browning, in contrast to the heat browning where sugars were mainly involved and the role of amino acids might be a catalyst.

The results in Table II concluded that amino acids and sugars were highly related to the browning of soy sauce on oxidation as well as on heating, too. The simple model system used in the present study, of course, can not completely represent the browning of soy sauce because many other amino acids than glycine and glutamic acid were suggested to contribute to the browning reaction. As to the role of the other amino acids in the browning of soy sauce will be dealt with elsewhere.
Acknowledgements. The author expresses his sincerest thanks to Dr. M. Fujimaki and Dr. H. Kato for their kind guidance and encouragement throughout this work. Thanks are due to Dr. M. Mogi, Dr. N. Iguchi and Dr. I. Koshiyama for theil encouragement.

\section{REFERENCES}

1) H. Kato, I. Yamada, K. Isaka and Y. Sakurai, Nippon Nogeikagaku Kaishi, 35, 412 (1961).

2) A. Okuhara, N. Saito and T. Yokotsuka, J. Ferment. Technol., 49, 272 (1971).

3) H. Hashiba, Nippon Nogeikagaku Kaishi, 45, 29 (1971).

4) F. Smith, Anal. Chem., 28, 350 (1956).

5) H. Rosen, Arch. Biochem. Biophys., 67, 10 (1957).

6) S. Omata, T. Ueno and Y. Nakagawa, Nippon Nogeikagaku Kaishi, 29, 256 (1955). 